\title{
Aproximación al estudio sobre el Modelo de mujer espiritual de los eclesiásticos en la Edad Moderna
}

\section{An approach to the study of the model of spiritual woman used by ecclesiatical men in Modern Age}

Francisco Pons Fuster

francisco.pons@uv.es

Universidad de Valencia

Resumen: El modelo de mujer espiritual, de beata, fue siempre el mismo a lo largo de la Edad Moderna. En todas las vidas de mujeres, los biógrafos siguieron un patrón o arquetipo y éste se reprodujo hasta bien entrado el siglo XVIII, y perduró hasta el siglo XIX. No obstante, es necesario profundizar en cada una de las biografías para comprender que cada vida de mujer fue también única y singular. Solamente de este modo cada una de estas mujeres podrá recobrar el protagonismo que tuvo.

Palabras clave: Beata, Edad Moderna, biografía, confesores, espiritualidad.

Abstract: The model of a spiritual woman, a laywoman (beata), was always the same all throughout Modern Age. In all women's lives, biographers followed a pattern or archetype and this was reproduced until well into the eighteenth century, and persisted up to the ninteenth century. However, it is necessary to explore each biography in more detail, to understand that each woman's life was also one and unique. Only in that way, each of those women will be able to recover the prominence they once had.

Keywords: Laywoman, Modern Age, biography, father confessor, spirituality. 
Francisco Pons. Aproximación al estudio sobre el modelo de mujer espiritual de los eclesiásticos en la Edad Moderna

\section{1.- El modelo de mujer espiritual}

En una sociedad sacralizada como la del Antiguo Régimen, el modelo de mujer espiritual experimentó pocas modificaciones. Desde los inicios del siglo XVI hasta la primera mitad del siglo XVIII, la Iglesia ofreció escaso margen a las mujeres que pretendieron vivir su espiritualidad más allá del mero ritualismo formalista de las prácticas religiosas (Pons Fuster 2014 y 2015).

Convento o matrimonio fueron las alternativas casi únicas que se ofertaron a las mujeres; por tanto, aquellas que quisieron dedicarse a una vida espiritual, que desecharon las alternativas que se les ofrecían, tuvieron que buscar sus propios caminos aun a riesgo de los peligros que les podía comportar.

Los ejemplos María de Santo Domingo, más conocida como la beata de Piedrahita, entre los dominicos, Isabel de la Cruz entre los franciscanos, Dominga Torres entre los dominicos valencianos, por citar solo algunos casos, demuestran que hubo mujeres que, al calor de los procesos de reforma que se llevaron a cabo en las diferentes órdenes religiosas a finales del siglo XV y en los inicios del siglo XVI, encontraron espacios intersticiales, casi liminares, en los que desarrollar su vida espiritual bajo el amparo de las órdenes religiosas. Y aunque a veces se produjeron episodios traumáticos como el de Isabel de la Cruz, condenada por alumbrada, o el de la beata de Piedrahita acosada por frailes de su propia orden, sin embargo, la fundación de nuevas instituciones religiosas en la primera mitad del siglo XVI, que necesitaban acreditarse socialmente, ofreció a las mujeres nuevos espacios para desarrollar sus vivencias espirituales. ${ }^{1}$ En el mismo sentido ayudaron las reformas descalzas de los carmelitas y de los franciscanos en la segunda mitad del Quinientos.

Es evidente, que los tiempos recios que se vivieron desde la Reforma luterana azuzó los miedos de la jerarquía eclesiástica, que hizo todo lo posible por salvaguardar una cierta ortodoxia, poco definida siempre tanto espacial, temporal e ideológicamente, que alejara el peligro de la herejía. Salvaguardas que se patentizaron en las condenas de los alumbrados castellanos, de los protestantes de Sevilla y Valladolid y en la promulgación del Índice de libros prohibidos de 1559. Pero ya en esas fechas, las mujeres habían encontrado no ya un camino, sino una auténtica avenida que les permitía vivencias espirituales en las que tenían cabida todo tipo de experiencias: meditaciones, raptos, visiones, revelaciones y, sobre todo, acceso a la altísima contemplación. Una avenida que se les facilitó, entre otros, por el magisterio de Juan de Ávila y de sus discípulos, por los jesuitas de la primera generación, por las reformas descalzas de Teresa de Jesús y de fray Pedro de Alcántara y, también, por personajes singulares como fray Luis de Granada y Juan de Ribera. Mujeres de Extremadura, de Castilla, de Andalucía, de Valencia y de otros lugares encontraron confesores y maestros de espíritu más o menos avezados en la guía espiritual que les abrieron la posibilidad de nuevas vivencias espirituales más allá de los rezos vocales reiterativos y sin sentido, de la asistencia a las ceremonias rituales y, en definitiva, de la religiosidad meramente formalista. Las hicieron protagonistas de sus propias experiencias.

1 La bibliografía es abundante sobre estas dos mujeres. Para una visión general, Beltrán de Heredia (1972); Bataillon (1979); Márquez (1980) y García Hernán (2013).

SCRIPTA, Revista internacional de literatura i cultura medieval i moderna, núm. 8 / desembre 2016 / pp. 268-286 ISSN: 2340-4841 · doi:10.7203/SCRIPTA.8.9299 
Francisco Pons. Aproximación al estudio sobre el modelo de mujer espiritual de los eclesiásticos en la Edad Moderna

En Extremadura, las intrépidas aventuras del dominico fray Alonso de la Fuente pusieron de relieve la existencia de un número abundante de mujeres, de beatas, que calificaba de alumbradas. Tras sus denuncias a la Inquisición, el inquisidor Montoya tomó cartas en el asunto para discernir los supuestos errores doctrinales que podían derivarse de sus prácticas espirituales. Fray Alonso, que narraba las primeras visitas de Montoya, manifestaba su abatimiento y su pesar por haber comenzado su visita inquisitorial.

\footnotetext{
Porque no se descubría de la dicha doctrina sino ayunos y disciplinas, oraciones, contemplaciones, cilicios, confesiones, comuniones; y si algunos granos se descubrían de doctrina mala y sospechosa, estaban tan atapados y confundidos con lenguaje de Dios y con sacramentos, que [no] lucía ni parecía lo malo a vueltas de tanto bueno. Y así vi muchas veces al inquisidor triste y desconsolado y temeroso, que no sabía qué hacer, porque todo lo que se escribía de Alumbrados eran cosas santas y benditas (Huerga 1978: 150).
}

Pero las pesquisas de fray Alonso dieron finalmente sus frutos, y la intervención de la Inquisición concluyó en el conocido auto de fe que se celebró en Llerena el 14 de junio de 1579. En dicho auto salieron 51 penitenciados, de los cuales sólo 19, entre ellos 9 mujeres, lo fueron por la secta y doctrina de los alumbrados (Huerga 1978: 532-539). Pero el resultado final, ante la ingente multitud de mujeres a las que se aludía, no hay que valorarlo de modo cuantitativo, ya que las denuncias de fray Alonso, las pesquisas inquisitoriales, el proceso y la condena lo que provocaron «fue una acentuación del miedo generalizado a determinadas vivencias espirituales y la adopción de muchas cautelas a la hora de exponer determinadas doctrinas espirituales, sobre todo las referidas a las experiencias místicas» (Pons Fuster 2012a: 225-226).

Los supuestos responsables de que «manadas» de mujeres, de beatas, fueran éstas casadas, solteras o viudas, optaran por un modelo de espiritualidad en el que participaban de modo activo, conjugando la vida ascética (ayunos, disciplinas, cilicios), oraciones o meditaciones, contemplación espiritual, frecuencia sacramental (confesión y comunión) y, también los Ejercicios Espirituales de Ignacio de Loyola y la lectura de las obras de fray Luis de Granada, eran, en unos casos, clérigos sin más, en otros, discípulos de Juan de Ávila o frailes franciscanos descalzos o «teatinos» (jesuitas), etc., amparados todos ellos por pastores tan comprometidos como los obispos de Badajoz Cristóbal de Rojas y Juan de Ribera. El que entre tanto número de mujeres y de clérigos se produjeran situaciones particulares de malas o sospechosas prácticas doctrinales o de conducta inmoral no empece su voluntad de compromiso por vivir de manera más intensa su vida espiritual, no conformándose con ser simples protagonistas mudas de una religiosidad formalista, que era la única que se les reservaba en su condición de mujeres. Y las acusaciones contra ellas de ser ignorantes y sin letras y de que a pesar de ello fueran capaces de acceder a la etapas más sublimes de la contemplación espiritual puede ser entendible desde una visión estrecha y cargada de una cierta misoginia de los teólogos escolásticos, pero no desde la visión más amplia y participativa, abierta también a los 
Francisco Pons. Aproximación al estudio sobre el modelo de mujer espiritual de los eclesiásticos en la Edad Moderna

laicos y, por tanto, a las mujeres, que propugnaban otros espirituales.

La reforma descalza de Teresa de Jesús fue otra alternativa en la que las mujeres cobraron protagonismo. Ahora estaríamos hablando de mujeres que decidieron voluntariamente enclaustrarse de por vida, ser monjas; pero no son ellas a las que nos referimos sino a dos casos concretos que Teresa de Jesús narró en sus Fundaciones. El primer caso refiere la vida singular de Catalina Cardona, su vida de retiro eremítico durante siete años, de mujer que decidió abandonar su vida de bienestar y optar por una vida de sacrificio dedicada a la espiritualidad y que, posteriormente, mudó profesando como beata carmelita en el convento de Pastrana. ${ }^{2}$ Pero es el segundo caso el que pretendemos resaltar, el de las mujeres de Villanueva de la Jara que no cejaron en su empeño hasta que Teresa decidió aceptarlas como monjas de su nueva fundación.

Cronológicamente, lo acontecido en Villanueva de la Jara es coetáneo a lo sucedido en Extremadura. En este caso se trataba de nueve mujeres que decidieron retirarse a una ermita a las afueras del pueblo y dedicarse a vivir comunitariamente su espiritualidad. Las primeras noticias sobre ellas le llegaron a Teresa de Jesús en 1576 cuando se encontraba en Toledo y un clérigo de Villanueva le trajo unas cartas del ayuntamiento pidiéndole «admitiese para monasterio nueve mujeres que se habían entrado juntas en una ermita (...) algunos años había, y vivían con tanto recogimiento y santidad, que convidaba a todo el pueblo a procurar cumplir sus deseos, que eran ser monjas.» ${ }^{3}$ En 1580, Teresa volvió a saber de la intención de estas mujeres por medio de dos frailes carmelitas del convento del Socorro, próximo a Villanueva. Finalmente, venció todos sus recelos sobre una fundación conventual de estas características y decidió trasladarse a Villanueva. Lo que vio allí le causó un profundo respeto tanto por la forma de vida que llevaban, como por el modo que seguían para ejercitarse en la vida espiritual.

\footnotetext{
Verdad es que estas hermanas que estaban aquí los han pasado (los trabajos) casi seis años; al menos más de cinco y medio que ha que entraron en esta casa de la gloriosa Santa Ana, dejada la mucha pobreza y trabajo que tenían en ganar de comer, porque nunca quisieron pedir limosna (la causa era porque no les pareciese estaban allí para que las diesen de comer), y la gran penitencia que hacían, así en ayunar mucho y comer poco, malas camas y muy poquita casa, que para tanto encerramiento como siempre tuvieron era harto trabajo. ${ }^{4}$
}

Entre las nueve mujeres había viudas y solteras, sólo una sabía leer, y se ejercitaban en sus ejercicios espirituales con la lectura de las obras de fray Luis de Granada y de fray Pedro de Alcántara. Y Teresa resaltó el aspecto físico que presentaban y la causa que lo provocaba: «estaban mal aliñadas,

2 Santa Teresa de Jesús, Libro de las fundaciones, www.portalcarmelitano.org/libros, cap. 28, números 21-33.

3 Ibidem, cap. 28, número 8.

4 Ibídem, cap. 13, número 38.

SCRIPTA, Revista internacional de literatura i cultura medieval i moderna, núm. 8 / desembre 2016 / pp. 268-286 ISSN: 2340-4841 · doi:10.7203/SCRIPTA.8.9299 
Francisco Pons. Aproximación al estudio sobre el modelo de mujer espiritual de los eclesiásticos en la Edad Moderna

y casi todas tan flacas, que se mostraba haber tenido vida de harta penitencia». ${ }^{5}$ Ella no tuvo dudas sobre la doctrina espiritual de estas mujeres espirituales, ni se planteó si eran mujeres ignorantes y de que fueran capaces de experiencias espirituales singulares, le bastó simplemente con elogiarlas y reconocerles su modelo de vida espiritual. A pesar de todo, Teresa de Jesús advertía siempre en sus obras de la necesidad de recurrir a consejeros cualificados al adentrarse en el proceso espiritual, en especial, las mujeres, añadiendo: «y hay muchas más (mujeres) que hombres a quien el Señor hace estas mercedes. Y esto oí al santo fray Pedro de Alcántara, y también lo he visto yo; que decía que aprovechaban mucho más en este camino que los hombres, y daba de ello excelentes razones, todas a favor de las mujeres» (Egido 2015: 30).

Coetáneos a los ejemplos de Extremadura y de Castilla, en Valencia hubo también mujeres que quisieron vivir su espiritualidad de manera mas experiencial y participativa. La llegada de los jesuitas a Valencia en los años cuarenta del siglo XVI, cuando todavía los Ejercicios Espirituales de Ignacio de Loyola no gozaban de aprobación oficial, no impidió que algunas mujeres de la ciudad acudieran a sus pláticas espirituales. Lo hicieron porque les atrajo su nueva espiritualidad ascética y porque ellos eran firmes defensores de ofrecerles el sacramento de la comunión que hasta esos momentos les estaba reservado a momentos muy determinados (Pons Fuster 2012b: 136-141). Y poco después de los jesuitas, la llegada de los franciscanos descalzos de fray Pedro de Alcántara y su rápida difusión por el territorio valenciano hizo que numerosas mujeres se sintieran atraídas por la rigurosidad de sus vidas y por las propuestas espirituales que les hacían. Los frailes descalzos tuvieron éxito entre las mujeres porque, comprometidos como estaban con una espiritualidad que sustentada en la ascética la transcendía abriéndola hasta las experiencias de la alta contemplación mística, se comprometieron a difundirla entre los laicos, fundamentalmente entre las mujeres, propiciando lo que hemos denominado, quizás de manera exagerada, una democratización de las experiencias espirituales (Pons Fuster 1991: 143-175).

Pero antes de la llegada de los jesuitas y de los franciscanos descalzos, hubo mujeres valencianas que, desechadas las alternativas de convento y de matrimonio, algunas también viudas, optaron por vivir solas o en comunidad su retiro de la sociedad dedicadas a la espiritualidad. Los nombres de algunas de ellas han perdurado hasta nosotros, y aunque no se sabe con certeza la forma de vida que llevaban, es fácil deducir que no se apartaban demasiado de los ejemplos vistos anteriormente. ${ }^{6}$ Algunas, como la ermitaña Dominga Torres, acabaron integrándose en un beaterio de la orden dominica, que llegó a contar con más de cincuenta mujeres (F. Pons 1991: 152). Otro ejemplo singular fue el del beaterio de la calle Renglons en Valencia, donde vivió algún tiempo Margarita Agulló, tras su venida de Xàtiva, hasta que se trasladó a vivir a una casa que le ofreció el arzobispo Juan de Ribera. Su ejemplo singular de espiritualidad no estuvo exento de persecuciones (Pons Fuster 2009: 269-300).

5 Ibidem, cap. 13, número 40.

6 Orellana, M. A. (1887) Tratado histórico apologético de las mujeres emparedadas, Valencia.

SCRIPTA, Revista internacional de literatura i cultura medieval i moderna, núm. 8 / desembre 2016 / pp. 268-286 ISSN: 2340-4841 · doi:10.7203/SCRIPTA.8.9299 
Francisco Pons. Aproximación al estudio sobre el modelo de mujer espiritual de los eclesiásticos en la Edad Moderna

Los ejemplos traídos a colación muestran que las mujeres que no optaron por el convento no siguieron un modelo idéntico de vivir su vida espiritual. Hubo quienes no desecharon o no pudieron desechar la vida matrimonial y que la compatibilizaron, guiadas por sus confesores, con sus prácticas espirituales. Pero, en general, fueron mujeres solteras o viudas las que optaron por vivir su espiritualidad, bien como ermitañas o en la soledad de sus casas o en habitáculos arrimados a las iglesias (emparedadas) o junto a alguna compañera o en beaterios, etc. Tampoco el modelo de vida espiritual, siendo similar, fue idéntico en todas ellas. Hubo quienes se conformaron con una vida espiritual circunscrita a la oración y a la meditación, otras prefirieron o destacaron por una vida de padecimientos físicos voluntarios, algunos inimaginables, otras trascendieron esta vida ascética y se adentraron por la alta contemplación mística, otras destacaron por sus visiones o revelaciones, etc. Cada una fue singular en sus experiencias. Otra cosa diferente es el modelo o patrón que de las vidas de estas mujeres nos ha llegado a través de los procesos inquisitoriales o de las crónicas de las órdenes religiosas o de biografías exclusivas.

En las crónicas de las órdenes religiosas figuran biografías de mujeres que destacaron por su vida espiritual. Y lo mismo acontece en las vidas que se escribieron de algunas mujeres singulares. Y hay que resaltar como dato positivo el interés de los cronistas por intercalar junto a las vidas de mayor o menor santidad de sus compañeros de hábito, las de numerosas mujeres unidas o supeditadas a ellos como beatas de la Tercera Orden. De un modo u otro, al narrar sus vidas, estaban reconociéndoles sus méritos personales y mostrando a la sociedad, sobre todo a las mujeres, la existencia de un camino singular, diferente a los estados del matrimonio o del convento. Por su parte, en el caso de las vidas de algunas mujeres beatas, el simple hecho de que algunos autores las hicieran protagonistas exclusivas de sus obras, independientemente ahora del motivo que les impulsó a ello, resulta de una extraordinaria relevancia para el conocimiento histórico de las vidas de las mujeres espirituales, sin olvidar el modelo de ejemplo que para las otras mujeres podían tener estas biografías.

En crónicas y en biografías, los autores reiteran, con pequeñas modificaciones o poniendo énfasis particular en determinados aspectos vitales, el mismo patrón de mujer espiritual. Pero, las vidas de las mujeres espirituales son vidas sin vida. Casi nunca se encuentra en ellas una narración que permita tener una visión amplia de cómo vivieron, evolucionaron, se comportaron, los amigos que tuvieron, sus necesidades o problemas, etc. Se reitera su sujeción a confesores o padres espirituales y en muchos casos no se aportan sus nombres. Todo queda circunscrito a detalles biográficos básicos, muchos reiterativos, para después aludir siempre a sus virtudes, mortificaciones, tentaciones, anhelos y experiencias espirituales, algún que otro milagro o revelación excepcional, influjo social y poco más. Los biógrafos se ajustan todos a un mismo patrón. Año de nacimiento, si se sabe, y año de su muerte, y entre una y otra fecha es difícil precisar, dada la parquedad de los datos, en qué momento de las vidas de estas mujeres acontecieron los hechos que se narran (F. Pons 2014: 182).

Adelina Sarrión alude al hecho de que todas las biografías de mujeres que se escribieron durante los siglos XVI y XVII siguieron siempre unos mismos arquetipos o patrones. En concreto citaba 
Francisco Pons. Aproximación al estudio sobre el modelo de mujer espiritual de los eclesiásticos en la Edad Moderna

como tales las biografías de santa Catalina, santa Ángela de Foligno y Margarita Porette (Sarrión 2003: 79-102). Por nuestra parte, la circunscribimos al ejemplo de Catalina de Siena, considerando la aceptación popular que esta santa tuvo en tierras valencianas desde finales del siglo XV (Pons Fuster 2012c). Y la coincidencia refuerza la idea de la reiteración del mismo modelo de mujer espiritual a lo largo de toda la Edad Moderna.

A edad temprana visión o visiones espirituales, ásperas disciplinas, se rehúyen los juegos infantiles, opción por la virginidad y aceptación de matrimonio espiritual. Después, penitencias, abstinencias, ayunos y aspereza de vida. Vestir hábito. Tentaciones de todo tipo. Visitas continuadas a iglesias o a una determinada iglesia conventual y elección de confesor. Experiencias espirituales. Humildad y caridad con los pobres. Compromiso religioso inducido, aceptación y profesión como beata. Fama y reconocimiento social de santidad. Revelaciones. Muerte. Posibles milagros. Todo lo referido figura en la vida de santa Catalina de Siena y lo mismo, como veremos de inmediato, se reproduce en las vidas de casi todas las mujeres espirituales. ${ }^{7}$

\section{2.- Mujeres protagonistas de las crónicas.}

Entre las numerosas biografías de mujeres que figuran en la Chrónica del franciscano descalzo Antonio Panes hemos escogido cuatro de ellas (Panes 1665-1666). Podríamos haber elegido las de aquellas mujeres que consiguieron más fama y que sus biografías son más amplias, como Isabel de Medina, Francisca Llopis o Elena Martínez, pero hemos preferido estas cuatro porque, ya olvidadas por casi todos, recobraran el protagonismo que tuvieron en su época y porque, además, se asemejan entre sí por el modelo de vida espiritual. En sus biografías, aunque se narran revelaciones y otras experiencias espirituales, se incide sobre todo en la vida voluntaria de padecimientos físicos, de sufrimientos, que escogieron. No se conocieron entre sí, pues vivieron en lugares bastante alejados y, además, ignoramos los nombres de sus confesores o guías espirituales, aunque suponemos que eran frailes franciscanos descalzos. El propio biógrafo dispuso solo de retazos de sus vidas, escritos por sus compañeros de hábito, por lo que poco pudo decir más allá de lo que aportamos ahora.

\section{Inés Castaño}

Inés Castaño nació en Murcia en la segunda mitad del siglo XVI y murió en la misma ciudad a las tres de la mañana del día 27 de julio de 1624, a los 60 años. Sus padres, «honrados, christianos viejos y de mediana hazienda para passar la vida con decencia» (Panes 1665-1666: I, 905). Huérfana muy pronto, se crió con su tutor y sus parientes. Rehuía casarse porque quería dedicar su vida a Dios, no obstante, forzada por el entorno familiar, se casó, lo que su biógrafo lamentó sobremanera porque

7 Pérez, Miguel (1499) La vida de sancta Catherina de Sena, València: Christófol Cofman; Capua, Ramon de (1511) La vida de la seráphica Catherina de Sena, ara novament per un devot affectat religiós della [Fra. Tomàs de Vesach O.P.] complidament arromançada, e de moltes istories istoriada, València: Johan Joffre de Brianso.

SCRIPTA, Revista internacional de literatura i cultura medieval i moderna, núm. 8 / desembre 2016 / pp. 268-286 ISSN: 2340-4841 · doi:10.7203/SCRIPTA.8.9299 
Francisco Pons. Aproximación al estudio sobre el modelo de mujer espiritual de los eclesiásticos en la Edad Moderna

«atropelló la carne grosera aquel lirio cándido, y casta açucena, que quería consagrar a Dios su virginidad» (Panes 1665-1666: I, 905).

A los tres meses de matrimonio, Inés quedó viuda. Sus parientes, «pareciéndoles que no era decente, que una muchacha viuda, y sola, se quedasse expuesta a los riesgos, que en semejante estado amenaçan, trataron de bolver a casarla». Incluso le eligen un nuevo marido. Pero ella, «con resolución varonil les atajó el intento», y para reafirmar su voluntad, se cortó el cabello y les manifestó que había hecho voto de castidad. Refrendó su decisión de vivir su nueva vida, renunciando a sus tutores (Panes 1665-1666: I, 905).

Inés Castaño tuvo como confesor a un franciscano descalzo del convento de San Diego de Murcia, quien le alentó para que adoptara el cambio radical de su vida. A partir de esos momentos, se ajustó a un nuevo modo de vivir, evitando que se murmurara de ella. Se vistió humildemente, rehuyó las visitas y conversaciones banales y decidió «estarse en su recogimiento continuamente, ocupada en el trabajo, y labor de sus manos, mediante el qual, y la hazendilla, que le avía quedado tenía para su sustento, y hazer alguna limosna a los pobres» (Panes 1665-1666: I, 906).

Su nueva vida no pasó desapercibida a sus vecinos, que se admiraban de ver a una mujer joven tan abstraída de las cosas «del siglo» y de vida tan ejemplar. Sus mismos confesores, sorprendidos por su modo de vida, la autorizaron para que comulgara todos los días y propusieron a sus prelados para que le dieran el hábito de beata. Inés tenía entonces 30 años y profesó un año después. A partir de esos momentos, a pesar de no disponer el biógrafo de demasiados datos de su vida, se resaltan algunos detalles que se reiterarán en las demás biografías de mujeres espirituales.

Inés Castaño comenzó una vida de penitente. Las penitencias con las que castigó su cuerpo se iniciaron cuando profesó como beata y perduraron hasta su muerte. Cabe inferir por ello, que fueron sus confesores, más que la voluntad de Inés, los que la arrastraron a domeñar sus pasiones con el castigo corporal. Día y noche andaba ceñida o de un «tallo de hoja de lata, o de una cadena de hierro con puntas azia dentro agudas.» No vestía camisa y andaba descalza, lo que maravillaba a su biógrafo, teniendo en cuenta «el delicado sugeto de una flaca muger no criada en trabajo.» Dormía en el suelo. No bebió jamás vino ni comió carne. Su comida ordinaria era «unas cortezas de pan seco, a las quales (añadía) algunos días unas yervas cozidas, sin poner en ellas azeite, sino solo vinagre, y otras vezes ceniza para quitarles más el sabor.» $Y$ en las festividades se regalaba con las cabezas de sardinas «que hallava en la calle y a veces en los muladares», lo que unido todo con las hierbas «era su banquete más regalado, y como tal avía de ser muy de quando en quando» (Panes 1665-1666: I, 907).

Inés Castaño tenía predilección por los pobres y sobre todo por los llagados, pues en ellos hallaba sus mayores deleites, ya que no se contentaba con curarles, sino que para vencer su natural asqueroso, les besaba las llagas «y lamiéndolas como si fuera un almíbar, chupava el malicioso humor, y se le tragaba.» La frecuencia de sus acciones acabó por provocarle una grave enfermedad, lo que forzó 
Francisco Pons. Aproximación al estudio sobre el modelo de mujer espiritual de los eclesiásticos en la Edad Moderna

al Guardián del convento de Murcia a prohibírselas. Ella obedeció, pero prosiguió atendiendo a los enfermos, a los que a veces les hacía una señal de la cruz con su saliva. Algunos llegaron a sanar de sus enfermedades (Panes 1665-1666: I, 908-909).

La fama de Inés Castaño se extendió por Murcia y a su entierro acudió la gente más principal. Los eclesiásticos no quisieron que los frailes la sepultaran en su convento y fue enterrada en la parroquia de San Antolín en la capilla de san Antonio (Panes 1665-1666: I, 911).

\section{Juana Godoya}

Juana Godoya nació en Callosa (Alicante) y murió en la misma ciudad el 1 de septiembre de 1622. Nada se sabe de sus padres, solamente «aver sido gente limpia, y honrada, y de mucha christiandad y virtud» (Panes 1665-1666: I, 846).

El inició de su espiritualidad se produjo cuando tenía siete años y su madre le enseñó la devoción, muy introducida en su pueblo, de rezar treinta Credos el día de Santiago apóstol, 15 por las necesidades presentes y otros 15 por la necesidades futuras. Esa misma noche fue

\footnotetext{
arrebatada en espíritu, y fue llevada al cielo su ánima, donde le fueron mostrados hermosíssimas salas, vergeles, y amenidades muy deliciosas, los coros Angélicos, y exércitos de los Ciudadanos triunfantes, y en fin tanta hermosura y gloria, que aunque ella lo dezía después con excessivo gozo, júbilo, y dulçura interior, siempre confessava, que no era posible explicar lo que avía visto, no obstante que el Ángel de su guarda le iva declarando el ser, y oficio de cada cosa, mas era su excelencia tanta, que bien se podría experimentar pero no dezir (Panes 1665-1666: I, 846).
}

El sueño de Juana fue calificado por su confesor de rapto, pero dejó una profunda huella en la niña, pues desde entonces «empeçó a hazer una vida de Ángel en carne», lo que le permitió guardar toda su vida la pureza virginal y no pecar jamás gravemente.

Entre las numerosas virtudes que adornaron la vida de Juana se destaca su austeridad y penitencias. Ya de niña era inclinada al rigor y a la aspereza, pero sólo después de tomar el hábito y de profesar como beata de la Tercera Orden fue cuando impulsó sus ejercicios de mortificación, «como obligatorios del nuevo estado.» Vestía un hábito de sayal grosero como el de los frailes descalzos, pegado al cuerpo, y para disimularlo llevaba «una gorguera de cosa de tres dedos de lienço, algo descubierta por el cuello, dando a entender que traía camisa», aunque no se la puso nunca. Dormía sentada, reclinada su cabeza sobre una piedra grande. Ya mayor, quebrantado su cuerpo por las enfermedades, se acostaba en un jergón de paja, aunque otros dicen que dormía sobre un arca. Ayunó toda su vida a pan y agua. Y en cuanto a los cilicios, llevaba uno de cuatro dedos de ancho con púas agudas hacia dentro, «que certifican los que le vieron, ser de los más inhumanos, que podía inventar la crueldad.» También llevaba unas planchas de rallo en el pecho y rodeaba su cuerpo con una gruesa cadena de hierro. Dominó totalmente sus pasiones. No levantaba los ojos del suelo 
Francisco Pons. Aproximación al estudio sobre el modelo de mujer espiritual de los eclesiásticos en la Edad Moderna

ni hablaba nunca mal de nadie. Era recatada y honesta. Su confesor no dudaba de la certeza de las visitas divina que ella le contaba (Panes 1665-1666: I, 847-848).

Juana Godoya vivió siempre del trabajo de sus manos y el tiempo que no se ocupaba en trabajar lo gastaba en la oración y en la contemplación. El anhelo de soledad la llevaba a veces a retirarse a casa de una amiga. «En fin, era común voz, que la santa Beata Godoya iva siempre absorta en profunda oración.» Tenía el don de revelación que practicaba en el ámbito doméstico para evitar escándalos si sus revelaciones no se cumplían. Manifestaba angustias y gemidos en sus raptos, los cuales, según certificaron su confesor y su médico, «procedían del doliente afecto, en que se encendía su coraçón, renovando la piadosa memoria de lo que el Salvador padeció.» Entre sus devociones estaban el realizar las estaciones del Vía Crucis de Callosa. Se le aparecía Nuestro Señor mostrándole sus llagas, unas más ennegrecidas que otras, las cuales estaban motivadas por «los Eclesiásticos, que aviéndolos elegido para que me sirvan con mayor perfección, con mayores pecados me ofenden.» Su fama se extendió por la comarca, hasta el punto que el obispo de Orihuela, Fray Andrés Balaguer, la visitó en su casa cuando estaba enferma, y al salir de la visita le dijo al médico: «Grande santa tienen en esta tierra y no la conocen: grande muger es esta» (Panes 1665-1666: I, 848-852).

Especial relevancia en la vida de Juana Godoya tuvo la presencia del demonio. Éste se le aparecía adoptando diversas formas. Unas como mastines rabiosos, otras veces veía como entraba en su aposento, cuando ella oraba de rodillas, «un espantoso tropel de puercos, y bufando, y haziendo temeroso estruendo, y ruido, la atropellavan, y echavan a rodar por el suelo», pero ella se armaba de valor, y con la señal de la cruz los vencía y ahuyentaba. Pero como más solía atormentarla era:

\footnotetext{
En la de un horrible y disforme negro, el qual quando la sierva de Dios, para dar algún alivio a su quebrantado cuerpo, se acostava en su gergoncillo de paja, el venía, y se echava a su lado haziéndola quanto mal podía: y la mayor molestia, que la causava, era una tan excessiva frialdad, que resultava dél, que el mismo yelo era templado en su comparación. Sufría ella con constante ánimo aquel intolerable martirio, hasta que satisfecho el Señor de su fe, le comunicava virtud para apartar de sí el enemigo, de cuya cercanía quedava fatigada en extremo (Panes 1665-1666: I, 852).
}

Los escasos datos biográficos no permiten confirmar en qué momento la beata Juana Godoya dejó de vivir en su casa, pero se sabe que los últimos años de su vida vivió en casa de Águeda Boyvía, posiblemente otra beata de Callosa.

Tras una larga y penosa enfermedad, Juana Godoya murió. En su testamento ordenó ser enterrada en el convento de los franciscanos descalzos de Callosa, pero antes de sepultarla los clérigos seculares decidieron hacerle las exequias fúnebres en la parroquia, y fue allí donde se obró el milagro de que la beata abriera los ojos y pestañeara. De inmediato, los asistentes empezaron a cortarle como reliquias todo lo que llevaba encima y entonces se decidió enterrarla en la sacristía de la iglesia parroquial (Panes 1665-1666: I, 853-854). 
Francisco Pons. Aproximación al estudio sobre el modelo de mujer espiritual de los eclesiásticos en la Edad Moderna

\section{María García González.}

María García nació en la Puebla de Don Fadrique, arzobispado de Toledo. Se ignora el año de su nacimiento, pero se sabe que murió el 15 de septiembre de 1630. No hay noticias sobre el nombre de sus padres, pero se cree que la beata era cristiana vieja (Panes 1665-1666: II, 154).

María García decidió consagrar a Dios su virginidad a la edad de 14 años. Su decisión no fue bien aceptada por sus padres, que pretendían casarla y, por ello, la maltrataban. «Dávanle cozes, bofetadas, y golpes, dezíanla afrentas, e injurias, y muchas vezes llegavan a darla de palos con grande corage, como si fuera una vil esclava.» Quiso ser beata, pero sus padres quisieron impedírselo de todas las maneras. Finalmente, tras su año de prueba, profesó como beata en el convento de Puebla (Panes 1665-1666: II, 154).

Cilicios y disciplinas y grandes ayunos. Toda una vida continua de ejercicios de piedad y mortificación, hasta el punto de quedar tan enflaquecida que su propio confesor le ordenó que comiera algunas viandas. Pero la vida de María se sublimaba a base de mortificaciones desproporcionadas. Así,

\footnotetext{
las noches claras de invierno (que en aquella tierra, y lugar de la Puebla, son rigurosíssimas) desnudándose en carnes, y abriendo las ventanas de par en par, se ponía al passo del ayre los braços en Cruz; y en esta forma se solía estar dos horas, y más, hasta sentirse toda penetrada del yelo, y entonces, para entrar en calor, hazía una cruel disciplina, hiriéndose de arriba abaxo todo su cuerpo con doblado dolor, por estar los miembros tan sensibles del frío, y desta suerte se açotava siempre. Después se recogía sobre su camilla, que era muy pobre, y sólo con su hábito se abrigava.
}

En la celebración del nacimiento de Jesús, María se iba a un pesebre y se desnudaba, y «allí se estava meditando la desnudez, y frío, que padecería aquel tierno, y delicado Niño...» (Panes 1665-1666: II, 155). Plasmaba de modo literal en su vida la imitación de la vida de Jesús. Si meditaba sus caídas con la cruz, se cargaba de leños y se dejaba caer en tierra para lastimarse. Otras veces cogía cosas de gran peso y subía las escaleras para dejarse caer y atormentarse con los golpes. «Y por acordarse de la amargura de la passión de su amado Jesús, tenía un vaso de hiel, y vinagre, del qual muchas vezes bevía...» (Panes 1665-1666: II, 155).

La devoción por la eucaristía era tan extremada, que incluso a nosotros nos resulta difícil entender sus acciones, pues llegaba hasta el punto de que:

\footnotetext{
Viniendo de comulgar una hermana suya, y aviéndosele rebuelto el estómago, y hecho un bómito muy copioso en una caçuela, ella le tomó con grande fervor, y por parecerle, que estarían allí las especies sacramentales, se bevió quanto avía trocado sin asco ninguno, porque el natural, que podía tener, lo venció el impulso sobrenatural (Panes 1665-1666: II, 155).
}

Sin interés material alguno, solamente por inducirlas a la virtud, enseñaba a «labrar a todas las niñas y donzellitas de su lugar.» Pocos datos más se recogieron de su vida, si acaso, narrar que su oración era sublime y extática, y que tenía dificultad para orar vocalmente porque enseguida se quedaba arrobada en altísima contemplación (Panes 1665-1666: II, 156). 
Francisco Pons. Aproximación al estudio sobre el modelo de mujer espiritual de los eclesiásticos en la Edad Moderna

\section{Ginesa de la Rosa}

Ginesa de la Rosa o María de la Concepción nació en Cartagena y murió en la misma ciudad el 12 de abril de 1632. Sus padres fueron Juan de la Rosa y Bárbara Celdrán, «ambos de linage limpio, y honrado, bien queridos, por vivir sin ofensa de nadie, y ser gente sincera, y de buen proceder, y de mediana hazienda para passar sin abatimiento» (Panes 1665-1666: II, 157).

Ginesa hizo voto de virginidad a los 13 años. Su decisión fue tan firme que «con varonil constancia se cortó el cabello, desnudóse de las pocas galas que usava, y dióselas a una hermana suya.» Para confirmar su voto, se juntó con otras mujeres y fue descalza al convento franciscano de San Ginés de la Xara. Allí se confesó y comulgó y confirmó su desposorio espiritual. De vuelta a casa se vistió con un hábito de san Francisco, pero no por orden de los religiosos, sino simplemente por devoción (Panes 1665-1666: II, 158). Los domingos por la tarde solía reunir a sus vecinas y les leía fragmentos de la Pasión del Señor «y otros libros santos» (Panes 1665-1666: II, 159).

Los franciscanos descalzos fundaron en Cartagena el convento de san Diego y Ginesa comenzó a frecuentarlos. Después, sabiendo que los frailes descalzos daban el hábito de la Tercera Orden con voto de obediencia y castidad, pidió ser admitida como beata, lo que consiguió con facilidad dada la fama de santidad que comenzaba a tener. Fue posiblemente entonces cuando mudó el nombre de Ginesa por el de María de la Concepción (Panes 1665-1666: II, 159).

La capacidad de mortificación de Ginesa sobrepasaba los ejemplos ya vistos de sus compañeras beatas. Ella tenía a raíz de las carnes cuatro cilicios: dos de cerdas ásperas en los brazos y otros dos de hierro en el pecho y la espalda. Si alguna vez se liberaba de ellos, se colocaba un escapulario tejido de esparto por una parte y de pleita por la otra. Pero, «el despertador más vivo de los dolores de su amado Jesús, era una Cruz con treinta y tres púas, que tenía arrimadas al pecho...» (Panes 1665-1666: II, 160). En cuanto a las disciplinas, se ejercitaba tres veces al día derramando a veces tanta sangre que era necesario limpiar el suelo y las paredes. Otras veces, para disciplinarse utilizaba «dos pares con canelones, y rosetas en los extremos». Lo hacía tan despiadadamente que con el ruido despertaba cada noche a una compañera suya que vivía en su casa. No conforme con tanta mortificación, la beata utilizaba otros modos.

Tenía una Cruz grande, mayor que la estatura del cuerpo, arrimada a la pared, un poco sacado el pie afuera, con tres clavos grandes; de los quales todas las noches estava pendiente tres horas, y muchas vezes perseverava las noches enteras puestos los pies en el clavo inferior, y colgado el cuerpo de los otros dos, enlaçando las manos en unos cordeles (Panes 1665-1666: II, 160).

La continua y afrentosa mortificación corporal le causaba dulzura. Pero todavía era capaz de más sacrificio, pues dormía de rodillas y así perseveró durante treinta años hasta que su confesor, por la cantidad de sangre que echaba por el pecho, la obligó a dormir de otro modo. Entonces, Ginesa 
Francisco Pons. Aproximación al estudio sobre el modelo de mujer espiritual de los eclesiásticos en la Edad Moderna

utilizó medio tablón de madera de cama, tan corto, que no le llegaba más que hasta las rodillas, durmiendo encorvada y con una piedra de almohada que después sustituyó por un madero (Panes 1665-1666: II, 160).

El cronista intercala juicios propios en las biografías. Así, el hecho de que Ginesa, al morir su hermana, durmiera en la habitación de sus sobrinas sentada sobre una silla, le merece la siguiente apostilla.

\footnotetext{
No puede quietarse, ni dormir, como dizen, a pierna suelta, el que peregrina, y anhela a la patria: ni es possible, que un corazón amante dexe de dar latidos, y golpes, para despertar, y aguardar al esposo con la lumbre encendida, no en lecho blando, que pega sueño, e infunde pereza, sino en cama, que, por su dureza, despida, y sacuda de sí, los miembros (Panes 16651666: II, 161).
}

Ginesa fue en sus ayunos «un perpetuo cuchillo de los apetitos, tomando muy escasamente lo que pedía la necessidad.» Ayunó desde los trece años hasta su vejez, cuando sus confesores le ordenaron que se abstuviera de ayunar. Como hecho a resaltar se narra que se pasó toda una Cuaresma sin probar gota de agua ni de vino como reverencia a lo que Jesucristo padeció en la cruz (Panes 16651666: II, 161).

El carácter imitativo de la Pasión se ajustó en las manifestaciones devocionales de Ginesa a la literalidad. Por eso, durante un año, todos los viernes subía descalza con una compañera a la montaña de San Juan, distante media legua de Cartagena. Llegada a la cima, permanecía durante tres horas con los brazos en cruz, a veces de rodillas (Panes 1665-1666: II, 161).

Ginesa vivía del trabajo de sus manos y su profunda humildad la hacía despreciar las estimaciones humanas, «porque como la tenían en opinión de santa, veneravanla como a tal, y encomendavanse en sus oraciones con gran oración, de que ella recibía gran pena». (Panes 1665-1666: II, 162). No se preocupaba del vestir, hasta el punto de que una compañera suya se avergonzaba de ir con ella por la calle por lo raído que llevaba el hábito o el manto. Soportaba todo con extraordinaria paciencia. El propio demonio rabiaba por la paz inalterable que veía «en esta varonil mugen». Socorría a los pobres y los visitaba en los hospitales. «Estava tan rendida, y sujeta a sus Prelados, y Confessores, que sin licencia suya no se atrevía a hazer mi aun una visita, lo mismo era en quanto a los exercicios penales, y govierno espiritual» (Panes 1665-1666: II, 163164). Murió con fama de santidad.

\section{3.- La santidad de las mujeres}

Las biografías seguían, como hemos visto, un patrón y reiteraban un mismo modelo de mujer espiritual, singularizando un aspecto u otro de sus prácticas o experiencias espirituales. Tenían un carácter ejemplificador para la sociedad y, sobre todo, para las mujeres. Sin embargo, hay aspectos en todas las biografías que merecen resaltarse como la proyección y el reconocimiento social que 
Francisco Pons. Aproximación al estudio sobre el modelo de mujer espiritual de los eclesiásticos en la Edad Moderna

las mujeres consiguieron, su dependencia y sometimiento a confesores o maestros de espíritu, su capacidad por hacer creíbles sus experiencias espirituales, algunas de ellas meras fantasías desproporcionadas, la supuesta anulación de su propia personalidad, su aceptación como maestras por los eclesiásticos de su entorno, las persecuciones que padecieron, etc. A algunos de estos aspectos hacía referencia H. Sánchez Ortega cuando ponía de relieve que el camino de la santidad era un aliciente para las mujeres.

\footnotetext{
La mujer que conseguía el apoyo y aprobación de sus superiores religiosos escalaba, a veces, cimas sociales que le hubieran estado vedadas desde cualquier otro trampolín, la admiración e incluso la posibilidad de que su vida se desenvolviera en medio de circunstancias de mayor atractivo intelectual y material -aún en medio de privaciones y penalidades físicas- que podían actuar como estímulo y anzuelo para cualquier jovencita o mujer madura dotada de imaginación, sensibilidad e inteligencia (Sánchez Ortega 1996: 165).
}

No obstante, diferenciaba entre la vía de la santidad seguida por muchas mujeres y feminismo, ya que muchas mujeres fueron impelidas hacia formas de vida que presuponían la anulación de su propia personalidad femenina, lo que comportó quizás la consolidación de un estereotipo negativo de la feminidad al traslucirse un modelo de mujer complacida con su sufrimiento (Sánchez Ortega 1996: 165). Ejemplos de ello se han visto en las beatas cuyas vidas aparecen en las crónicas. En algún caso, la complacencia que sentían por el sufrimiento las conducía a realizar acciones desorbitadas como chupar las llagas, tragarse vómitos o someter su cuerpo a todo tipo de privaciones y ejercicios penales. Fueron ejercicios voluntarios o impuestos por sus confesores, ahora bien, que significaran la anulación de su propia personalidad femenina no estamos en condiciones de dilucidarlo con absoluta precisión. Pero, independientemente de ello, creemos que las mujeres espirituales dispusieron de cierta autonomía para articular su espiritualidad y en algún caso fueron capaces de mantener espacios de libertad personal a expensas de sus confesores.

Las mujeres espirituales, según Sánchez Ortega, buscaron el amparo o respaldo de los varones espirituales casi como una necesidad inexcusable, pues «resultaba muy difícil que una mujer pudiera superar las barreras sociales sin la ayuda, de una forma u otra, de su brazo masculino» (Sánchez Ortega 1996: 193). Por su parte, A. Atienza, sobre la misma idea aunque remarcando la independencia y autonomía de las beatas, afirma:

\footnotetext{
Creo que se ha impuesto y permanece una tendencia a considerar el mundo de las beatas fundamentalmente como un mundo libre de tutela y subordinación, un mundo sin mediaciones masculinas ni intromisiones eclesiásticas para las mujeres, y que en definitiva sobresale una propensión a acentuar la autonomía y la independencia vital de estas mujeres (Atienza 2008: 145).
} 
Francisco Pons. Aproximación al estudio sobre el modelo de mujer espiritual de los eclesiásticos en la Edad Moderna

En ambos casos no hay contradicción, pues era verdad que las mujeres buscaron la tutela y amparo de los hombres, y en este sentido no hay más que recordar lo que ya se ha dicho de Ginesa de la Rosa: «Estava tan rendida, y sujeta a sus Prelados, y Confessores, que sin licencia suya no se atrevía a hazer mi aun una visita, lo mismo era en quanto a los exercicios penales, y govierno espiritual». (Panes 1665-1666: II, 163-164). Pero, también es cierto que gran parte de la vida de las mujeres se desarrollaba con una gran independencia. Incluso, muy pocas tuvieron un único confesor a lo largo de su vida y muchas demostraron una gran capacidad para hacerles creer que el camino espiritual que seguían o las prácticas espirituales en las que se ejercitaban, aunque se alejaran de los mandatos que les imponían, no significaban desobediencia, ya que les eran ordenadas directamente por un maestro de mayor autoridad, su Esposo celestial. Incluso, por boca de ellas, pues eran ellas las que se lo transmitían, la propia divinidad comunicaba sus consejos a sus confesores. El caso más evidente, y no es el único que puede referirse, es el de la beata Luisa Zaragozá cuando con el respaldo de una revelación divina le dirigía a su confesor estas palabras:

\footnotetext{
Dile a tu padre espiritual, que ya que yo le he contentado, haciendo en ti lo que él ha querido, que ahora me contente él a mí. Te he sustentado con pan solo, con yervas solas, y con la comunión sola, para que él, y los que le ayudan a cuidar del govierno de tu alma, conozcan mi poder, y quán bueno soy para ti. Ahora exceptando la comida de carne, te puede hacer comer de ayuno lo que él quiera, que no te hará mal (Ortí Mayor 1749: 415-416).
}

A veces, el varón espiritual estaba dispuesto a apoyar a la mujer espiritual aún a riesgo de sufrir persecuciones. Así aconteció en los primeros tiempos de la relación que mantuvieron el franciscano descalzo Antonio Sobrino y la beata Francisca Llopis. La comunicación entre ambos tenía lugar cada ocho días. Ella acudía a la iglesia del convento de San Juan de la Ribera de Valencia y él tenía ordenado al portero de su convento que cuando ella llegara le avisara, aunque estuviera enfermo. Su estrecha relación provocó todo tipo de murmuraciones, pues los veían a los dos escribiendo con todo secreto. Incluso se afirmaba que la beata le había escrito a su anterior confesor, el jesuita Miguel de Fuentes, algunos papeles «que no eran seguros», pues había prometido sanaciones que no se habían cumplido. Decían también que el empeño de Sobrino en tratar a la beata le "ponía en grande peligro de ser afrentado por el Santo Oficio de la Inquisición, y por él nuestra Descalçez». El Provincial «intentó desbaratar la comunicación, y echar del Convento a la Madre Francisca». Pidió a un compañero de hábito para que advirtiera a Sobrino «los inconvenientes, que se seguían, y peligros, que amenaçavan de aquella correspondencia, y le amonestasse el dexarla, y le diesse assí mismo un papel sin firma de parte de ciertos zelosos del bien común» (Panes 1665-1666: I, 785).

Sobrino satisfizo con razones al compañero y contestó al escrito afirmando que las sospechas, «que avían concebido contra aquella donzella tan honesta, recogida, y humilde», eran maliciosas y sin fundamento. No convencieron sus argumentos a sus émulos, que decidieron recurrir al 
Francisco Pons. Aproximación al estudio sobre el modelo de mujer espiritual de los eclesiásticos en la Edad Moderna

inquisidor Gabriel Pizarro para que consiguiera «que despidiesse aquella muger, (que ellos llamavan embaucadora e illusa)». Pero el inqusidor salió convencido del buen espíritu de la beata Francisca Llopis (Panes 1665-1666: I, 786).

En ocasiones, los confesores eran poco expertos en la guía espiritual y les asaltaban dudas sobre el camino espiritual de las mujeres por lo que se veían impelidos a demandar el consejo de otros eclesiásticos o a recurrir a los inquisidores para que ellos certificaran la ortodoxia y buena doctrina de las mujeres. Así aconteció con el joven confesor de la joven beata Luisa Zaragoza, que no se quedó tranquilo hasta que le certificaron la excelencia del camino espiritual que seguía su ahijada. Hubo también confesores que trastornaron las vidas de las mujeres y las impelieron a llevar a cabo acciones, que bajo el manto de la perfección espiritual, sólo buscaban satisfacer sus bajas pasiones (Pons Fuster 2008).

Los varones eclesiásticos avalaron las santidades de las mujeres. Lo hicieron como confesores o guías espirituales de ellas, pero no se conformaron con este trabajo sino que quisieron que su relación perdurara en el tiempo, y para ello escribieron a dictado las narraciones maravillosas que les contaban o les ordenaron a ellas que escribieran sus revelaciones y sus experiencias espirituales. En el pensamiento de algún confesor se entrevía la posibilidad de haber encontrado a una mujer que podría posteriormente ser considerada como santa. Como afirma, L. Sánchez Hernández alguno de ellos pretendía tener su santa Teresa particular «a la que podía mostrar como ejemplo de santidad» (Sánchez Hernández 2015: 47) Por tanto, en su fuero interno, al narrar sus vidas o al obligar a las mujeres a que lo hicieran estaban satisfaciendo su propia vanagloria, ya que la posible santidad de las mujeres, sería obra suya y estaría siempre ligada a su propio nombre, pues serían ellos lo que habrían moldeado y avalado su santidad.

Pero las mujeres espirituales también fueron utilizadas como avalistas de la santidad de vida de los frailes o de los eclesiásticos con los que se relacionaban. De este modo, las beatas Francisca Llopis, Isabel de Medina y Josefa Ripoll testimoniaron la santidad de vida de Fray Antonio Sobrino (Panes 1665-1666: I, 708-709). Lo mismo aconteció con la santidad de Fray Gabriel Gómez, avalada por los testimonios de Isabel de Medina, por otras hijas suyas espirituales de la ciudad de Loja (María Morillo), la beata María Rosales y Dorotea Gasque, «señora principal de Valencia», entre otras (Panes 1665-1666: II, 74-78).

La popularidad e influencia social conseguida por algunas mujeres podía dar lugar, como afirma $\mathrm{H}$. Sánchez Ortega, a que otras mujeres «sucumbieran ante la tentación de simular que eran objeto de las ansiadas revelaciones y dones sobrenaturales, sin excluir los estigmas». Lógicamente, en estos casos los peligros eran grandes si además intervenía la Inquisición, «pero la tentación, es preciso reconocerlo, tenía que resultar casi irresistible para aquellas que pensaran que podían sortear con éxito este peligro y alcanzar una notoriedad similar» a las de las mujeres excepcionales (Sánchez Ortega 1996: 155-156). Este, indudablemente podía ser un motivo para que determinadas mujeres 
simularan sus experiencias espirituales y los dones que recibían. En algún caso se refiere la gracia espiritual de los estigmas. Así aconteció con la beata Margarita Agulló, si bien, su biógrafo se cuidó mucho de disimularlos bajo el eufemismo de «un señal colorado» en el pecho o del simple sentimiento, que no realidad palpable, de los estigmas. Y lo mismo, aunque de modo todavía más disimulado, se refirió de la beata Isabel de Medina (Panes 1665-1666: II, 215). Y aunque en el primer caso hubo persecuciones contra ella y murmuraciones debido a su espiritualidad extremada, la fama y reconocimiento social de las dos mujeres citadas no se resintió de ningún modo. Con todo, hemos de reconocer que no estamos en condiciones de discernir los motivos últimos que llevaron a las mujeres a formas de vida espiritual tan extremadas. Y desde luego, aunque supusiéramos que en muchos casos fueron simulaciones de vida espiritual, hay que admitir el mérito que tuvieron de hacer creíbles a la sociedad y, sobre todo a los eclesiásticos que pululaban a su alrededor, sus supuestas fantasías, y que ellos mismos nos las dejaran escritas.

En conclusión, el modelo de mujer espiritual, de beata, fue el mismo a lo largo de la Edad Moderna. En todas las vidas de mujeres, como hemos tratado de probar, se siguió un patrón o arquetipo y este se reprodujo hasta bien entrado el siglo XVIII, y perduró hasta el siglo XIX. No obstante creemos que es necesario profundizar en cada una de las biografías para comprender que cada vida de mujer fue también única y singular. Solamente de este modo cada una de estas mujeres podrá recobrar el protagonismo que tuvo. 
Francisco Pons. Aproximación al estudio sobre el modelo de mujer espiritual de los eclesiásticos en la Edad Moderna

\section{Bibliografía}

Atienza, A. (2008) Tiempo de conventos. Una historia social de las fundaciones en la España Moderna, Madrid: Marcial Pons.

Bataillon, M. (1979) Erasmo y España, Madrid: Fondo de Cultura Económica;

Beltrán de Heredia, V. (1972) «La pseudoreforma intentada por la beata de Piedrahita y los procesos de esta religiosa», en Miscelánea Beltrán de Heredia, III, Salamanca, pp. 78-269.

Capua, Ramon de. (1511) La vida de la seráphica Catherina de Sena, ara novament per un devot affectat religiós della [Fra. Tomàs de Vesach O.P.] complidament arromançada, e de moltes istories istoriada, València, Johan Joffre de Brianso.

Cazorla, B. A. (1744) Vida y virtudes de la angelical y extática virgen la venerable Gerónima Dolz, doncella de puríssimas costumbres, muy favorecida de Dios, de la Virgen Santíssima y los Ciudadanos del cielo, Valencia.

Egido, T. (2015) «La madre Teresa de Jesús, mujer espiritual en tiempos de Contrarreforma», en J. Burrieza Sánchez (ed.), El alma de las mujeres. Ámbitos de espiritualidad femenina en la modernidad (siglos XVI-XVIII), Valladolid, Ediciones Universidad de Valladolid, pp. 23-38.

García Hernán, E. (2013) Ignacio de Loyola, Madrid, Taurus.

Huerga, A. (1978) Historia de los Alumbrados. I.- Los alumbrados de Extremadura (1570-1582), Madrid, Fundación Universitaria Española.

Márquez, A. (1980) Los alumbrados. Orígenes y filosofía (1525-1559), Madrid, Taurus.

Ortí Mayor, V. (1749) Vida, virtudes y favores de la Venerable Luisa Zragozá, llamada comúnmente Luisa de Carlet, Valencia.

Panes, A. (1665-1666) Chrónica de la provincia de S. Juan Batista de religiosos menores de la regular observancia de nuestro padre serápbico S. Francisco, Valencia.

Pérez, Miguel. (1499) La vida de sancta Catherina de Sena, Valencia, Christófol Cofman.

Pons Fuster, F. (1991) Místicos, beatas y alumbrados, Valencia, Institució Alfons el Magnànim.

- (2008) «Monjas y beatas. Mujeres en la espiritualidad valenciana de los siglos XVI y XVII», en E. Collado Estela (Coord.): Valencianos en la Historia de la Iglesia, II, Valencia, Facultad de Teología San Vicente Ferrer, pp. 187-276.

. (2009) «El Patriarca y la espiritualidad franciscana», Curae et studii exemplum. El patriarca Ribera cuatrocientos años después, E. Callado Estela (coord.), Valencia, Universitat de València, pp. 269-300.

—_. (2012a) «La espiritualidad del patriarca Juan de Ribera», en E. Callado Estela (ed.), El patriarca Riberay su tiempo. Religión, cultura y política en la Edad Moderna, Valencia, Institució Alfons el Magnànim, pp. 215-242.

. (2012b) «Cultura i Religió a Gandia a la primera meitat del segle XVI», en S.La Parra\&M. Toldrà (ed.), Francisco de Borja (1510-1572), hombre del Renacimiento, santo del Barroco, Gandia, CEIC Alfons el Vell et alia, pp. 131-151.

SCRIPTA, Revista internacional de literatura i cultura medieval i moderna, núm. 8 / desembre 2016 / pp. 268-286 ISSN: 2340-4841 · doi:10.7203/SCRIPTA.8.9299 
Francisco Pons. Aproximación al estudio sobre el modelo de mujer espiritual de los eclesiásticos en la Edad Moderna

- (2012c) «Mujeres profetisas. Un modelo de proyección social en la Edad Moderna», en Herejes, monjas, brujas y profetisas. Religiosidad femenina en la Modernidad, Alicante, Universidad de Alicante.

- (2014) «Mujeres espirituales. Modelos de vida tradicionales para las mujeres valencianas en la primera mitad del siglo XVIII. El ejemplo de Luisa de Carlet», en E. Callado Estela (ed.), La catedral ilustrada. Iglesia, sociedad y cultura en la Valencia del siglo XVIII», Valencia, Institució Alfons el Magnànim, pp. 181-202.

- (2015) «Modelos de mujeres espirituales. El ejemplo de las beatas valencianas y su evolución histórica», en J. Burrieza Sánchez (ed.), El alma de las mujeres. Ámbitos de epiritualidad femenina en la modernidad (siglos XVT-XVIII), Valladolid, Ediciones Universidad de Valladolid, pp. 211-238.

Sánchez Hernández, M. L. (2015) «Mariana de San José y "sus” Cuentas de Conciencia: género líterario y experiencia mística», en J. Burrieza Sánchez, El alma de las mujeres. Ámbitos de espiritualidad femenina en la modernidad (siglos XVI-XVIII), Valladolid, Universidad de Valladolid, pp. 39-72.

Sánchez Lora, J. L. (1988) Mujeres, conventos y formas de la religiosidad barroca, Madrid, Fundación Universitaria Española.

Sánchez Ortega, H. (1996) Confesión y trayectoria femenina: vida de la Venerable Quintana, Madrid, Consejo Superior de Investigaciones Científicas.

Sanchis, J. (1607) Relación breve de la vida, virtudes y milagros de la bumilde Sierva del Señor Sor Margarita Agullona, beata professa de la orden del Seráfico padre S. Francisco, Valencia.

Sarrión, A. (2003) Beatas y endemoniadas. Mujeres heterodoxas ante la Inquisición siglos XVI a XIX, Madrid, Alianza Editorial.

SCRIPTA, Revista internacional de literatura i cultura medieval i moderna, núm. 8 / desembre 2016 / pp. 268-286 